\title{
Erratum to: Sorption behavior of the oxytetracycline antibiotic to two Brazilian soils
}

Sílvio Vaz Jr.

\section{Erratum to: Chem. Biol. Technol. Agric. (2016) 3:6 \\ DOI 10.1186/s40538-016-0056-6}

Unfortunately, the original version of this article [1] contained an error. The Conclusions in both the Abstract and main text were incorrect. The Abstract Conclusions should have read "The sorption capacity (represented by $K_{\mathrm{d}}$ ) was quantified as high, denoting a non-achievement of the groundwater by the antibiotic OTC."

The main text Conclusions should have read "There was a relatively strong sorption of OTC to Brazilian soils, where it was dependent on the OM content, denoting a non-potential risk to the environment arising from their sorption capacity to such soils, making it not available to transport the antibiotic to the groundwater. OTC adsorption to soil obeyed Freundlich isotherm (L-type), for a multilayer OTC deposition on the soil surface. From such findings, it is reasonable to assume the need for further studies related to this subject to produce data enabling stipulate the maximum values allowed for the presence in soil."

The online version of the original article can be found under doi:10.1186/s40538-016-0056-6.

Received: 18 April 2016 Accepted: 18 April 2016

Published online: 05 May 2016

\section{Reference}

1. Vaz S Jr. Sorption behavior of the oxytetracycline antibiotic to two Brazilian soils. Chem Biol Technol Agric. 2016;3:6.

\footnotetext{
*Correspondence: silvio.vaz@embrapa.br

Brazilian Agricultural Research Corporation, National Research Center

for Agroenergy (Embrapa Agroenergy), Parque Estação Biológica, s/n, Asa
}

Norte, Brasília, DF 70770-901, Brazil 